\title{
Single cell cultures of Drosophila neuroectodermal and mesectodermal central nervous system progenitors reveal different degrees of developmental autonomy Karin Lüer and Gerhard M Technau*
}

Address: Institute of Genetics, University of Mainz, 55099 Mainz, Germany

Email: Karin Lüer - lueer@uni-mainz.de; Gerhard M Technau* - technau@uni-mainz.de

* Corresponding author

This article is available from: http://www.neuraldevelopment.com/content/4/I/30

(c) 2009 Lüer and Technau; licensee BioMed Central Ltd.

This is an Open Access article distributed under the terms of the Creative Commons Attribution License (http://creativecommons.org/licenses/by/2.0), which permits unrestricted use, distribution, and reproduction in any medium, provided the original work is properly cited.

\begin{abstract}
Background: The Drosophila embryonic central nervous system (CNS) develops from two sets of progenitor cells, neuroblasts and ventral midline progenitors, which behave differently in many respects. Neuroblasts derive from the neurogenic region of the ectoderm and form the lateral parts of the CNS. Ventral midline precursors are formed by two rows of mesectodermal cells and build the CNS midline. There is plenty of evidence that individual identities are conferred to precursor cells by positional information in the ectoderm. It is unclear, however, how far the precursors can maintain their identities and developmental properties in the absence of normal external signals.
\end{abstract}

Results: To separate the respective contributions of autonomous properties versus extrinsic signals during their further development, we isolated individual midline precursors and neuroectodermal precursors at the pre-mitotic gastrula stage, traced their development in vitro, and analyzed the characteristics of their lineages in comparison with those described for the embryo. Although individually cultured mesectodermal cells exhibit basic characteristics of CNS midline progenitors, the clones produced by these progenitors differ from their in situ counterparts with regard to cell numbers, expression of molecular markers, and the separation of neuronal and glial fate. In contrast, clones derived from individually cultured precursors taken from specific dorsoventral zones of the neuroectoderm develop striking similarities to the lineages of neuroblasts that normally delaminate from these zones and develop in situ.

Conclusion: This in vitro analysis allows for the first time a comparison of the developmental capacities in situ and in vitro of individual neural precursors of defined spatial and temporal origin. The data reveal that cells isolated at the pre-mitotic and pre-delamination stage express characteristics of the progenitor type appropriate to their site of origin in the embryo. However, presumptive neuroblasts, once specified in the neuroectoderm, exhibit a higher degree of autonomy regarding generation of their lineages compared to mesectodermal midline progenitors. 


\section{Background}

The central nervous system (CNS) represents the organ with the highest structural complexity and cellular diversity. Normal function of the CNS requires the generation of specific types and numbers of neuronal and glial cells during development following a reproducible spatio-temporal programme. Accordingly, the process conferring individual identities and properties to neural stem cells is fundamental and is a major issue in developmental neurobiology. The availability of a broad range of molecular and genetic tools as well as micromanipulation techniques have made Drosophila a suitable model organism to study this process at the level of individually identifiable cells.

The Drosophila CNS develops from two different populations of progenitor cells. Comprising the vast majority of neural precursors, the neuroblasts (NBs; about 30 per truncal hemisegment) generate the prominent lateral parts of the CNS. They delaminate individually in a specific spatio-temporal pattern from the neurogenic region of the ectoderm after a process of lateral inhibition that separates them from presumptive epidermoblasts. The second group of progenitor cells gives rise to the CNS midline. They are located ventrally between the neuroectoderm and the mesodermal primordium as one continuous row of cells on either side (three to four cells per hemisegment), which meet at the ventral midline upon invagination of the mesoderm during gastrulation. All of these mesectodermal cells become CNS midline progenitors.

Generally, NBs act like stem cells, generating a number of secondary precursors (called ganglion mother cells (GMCs)) by asymmetric divisions, which normally divide once to produce two post-mitotic progeny. Each of the NBs assumes an individual identity, as reflected by the expression of a specific combination of molecular markers $[1,2]$ and the generation of a specific cell lineage [3-5]. Specification of the individual NB fates occurs in the ectoderm based on positional information provided by the products of segment polarity genes [6], dorsoventral patterning genes [7], homeotic genes [8], and temporal cues [9]. The respective developmental traits conferred by these factors become manifested in neuroectodermal progenitor cells to different degrees [9-11]. Although most of the factors controlling specification of presumptive NBs appear to act in the neuroectoderm, it is still an open question whether NBs upon delamination from the neuroectoderm express their specific fate autonomously or whether they require inductive signals from surrounding tissues. It has been recently shown by in vitro culture experiments that embryonic NBs require extrinsic signals from the overlying epithelium for orientation of their division axis [12]. However, as to how far these or other extrinsic signals are required for the expression of further characteristics or the maintenance of NB fate and, thus, for the production of their characteristic lineages is unknown.

The second set of progenitor cells, the CNS midline progenitors, behave differently from NBs in many respects [13-15]. Similar to the floor plate in vertebrates, the Drosophila ventral midline acts as an organizing centre, as it influences cell fate in the lateral CNS [16-20], and is essential for proper organization of the axonal network [21]. In contrast to the NBs, the segmental number of mesectodermal midline progenitors is variable (six to eight cells per segment) [22]. During embryogenesis they give rise to about 20 functionally diverse cells, including interneurons, motoneurons and glial cells belonging to five different types of lineages (four neuronal and one glial type) [22]. Except for the median NB (MNB), which divides in a stem cell mode, midline progentior cells (with regard to geometry) perform equal divisions. A large number of genes have been found to be expressed in the midline, and individual precursors and progeny cells differ by the combinations of genes they express, reflecting a high degree of cellular diversity [15,23-25]. It has been recently shown that several aspects of midline cell fate become determined after division of the precursors by intercellular communication among progeny cells involving Wingless, Hedgehog [23] and Notch [15] signalling. Here we ask to what extent pre-mitotic midline progenitor cells (similar to NBs; see above) require positional cues and/or early inductive signals in the (mes)ectoderm for normal specification.

In order to investigate the dependency of the two sets of CNS progenitor cells on extrinsic versus intrinsic signals, we assayed their cell-autonomous developmental capabilities. We developed a strategy to remove cells from specific positions in embryos shortly after onset of gastrulation and growing them individually in culture. At the early gastrula stage, ectodermal precursor cells have just completed cellularization and have not yet entered postblastodermal mitosis, and their positions can be precisely determined due to the presence of first morphological landmarks. Since the normal lineages of all CNS midline precursors [22] and all truncal NBs, as well as their sites of origin in the neuroectoderm, are known [3-5], a direct comparison between the cultured clones and specific neural lineages in situ was possible.

The development of cultured neuroectodermal and midline progenitors was traced using time-lapse analysis and cell-specific molecular markers. We find that clones produced by cultured midline precursors differ from their in situ counterparts with regard to cell numbers and the expression of neuronal versus glial markers, whereas cul- 
tured neuroectodermal precursors develop striking similarities to specific NB lineages in situ with regard to division pattern, clone size and marker gene expression.

\section{Results \\ Development of mesectodermal midline progenitors in single cell cultures}

Cells were removed from the ventral midline at embryonic stage 7/8 upon invagination of the mesodermal primordium (Figure 1A) when the two rows of mesectodermal progenitor cells are facing each other and become clearly distinguishable at both sides of the ventral furrow. At this stage midline progenitor cells have not yet entered mitosis. Single progenitor cells were transferred into the culture medium and allowed to develop further for 16 to 20 hours, which corresponds to the time required for normal embryos to fully develop (stage 16/ 17).

\section{Distribution of clone sizes}

Each of the cultured midline precursors $(\mathrm{n}=896)$ gave rise to two to four progeny cells (Figure 1B-I); 37\% ( $\mathrm{n}=331)$ of their clones consisted of two cells, $19 \%(n=173)$ of three cells, and 44\% ( $\mathrm{n}=392)$ of four cells. We never found clones consisting of more than four cells. This significantly differs from the situation in situ [22], in which about $75 \%$ of DiI-labelled midline clones (at stage 16/17) consisted of only 2 cells (including the MP1, UMI, midline glia, and most of the VUM clones), about 7\% comprised 4 cells ( $15 \%$ of the VUM clones, and a few mixed lineages; see below), and about $18 \%$ comprised 5 to 8 cells (including the MNB and $6 \%$ of the VUM clones). Midline clones consisting of three cells are very rare exceptions in vivo (Table 1).

\section{Division pattern}

Using time-lapse recordings, we traced the division patterns of cultured midline precursor cells $(n=41)$. In all cases the divisions were morphologically symmetrical (Figure 1B). The first division takes place 40 to 55 minutes after gastrulation (when cells were taken into culture), which is similar to the in vivo situation (about 40 minutes) [22]. Subsequently, one (three-cell clones) or both daughter cells (four-cell clones) may divide one more times within 3 to 7 hours after gastrulation. In the embryo, NBs and one of the midline precursors, the MNB, divide asymmetrically several times to self renew. We never found such a stem cell mode of division for isolated midline precursors in vitro.

\section{Differentiation}

As judged by morphological criteria, cultured midline cells differentiated into neuronal and glial cell types. Neuronal cells showed small spherical cell bodies and developed long fibres that project in various directions (Figure
1C) or fasciculate with each other (Figure 1D). Glial cells typically show flat and elongated cytoplasmic extensions (Figure 1E). According to these criteria, $4.4 \%$ of the clones were glial and $78.4 \%$ neuronal. In addition $17.2 \%$ of the clones appeared to consist of both types of cells (Figure 1G-I). In the embryo, six midline precursors per segment (one MP1, one UMI, one MNB, three VUM; for different nomenclature see [15]) generate neurons exclusively, and one to three precursors (the exact number is unknown) produce only glia. Midline glia and neurons normally share common lineages only in exceptional cases (about $1 \%$ of DiI labelled clones were compound MP1/midline glia clones [22]; Table 1).

The existence of mixed neuronal/glial clones in vitro is further supported by cell-specific molecular markers. Applying the neuronal marker anti-horse radish peroxidase (anti-HRP; $\mathrm{n}=12$ ), clones were entirely labelled in only $50 \%$ of the cases (Figure 1C, D), whereas labelled and unlabelled cells coincide in the other $50 \%$. Similar observations were made using anti-Tramtrack (TTK) antibodies $(\mathrm{n}=50$; Figure $1 \mathrm{~F}, \mathrm{H})$ and the enhancer-trap line AA142 ( $\mathrm{n}=188$; Figure $1 \mathrm{E}, \mathrm{G}, \mathrm{I}$ ) as markers for midline glia $[14,26,27]$. These led to partially labelled clones in $46 \%$ $(\mathrm{n}=23$; Figure $1 \mathrm{~F}))$ and $37 \%(\mathrm{n}=70)$ of cases, respectively. Upon double labelling with both midline glia markers, AA142 and anti-TTK, we found several cases ( $\mathrm{n}=$ 10 ) in which the individual progeny cells expressed only one of these markers (data not shown).

Next, we performed double labelling against anti-HRP and anti-TTK or AA142. Out of 45 clones, 30 were positive for one, and 15 were positive for both markers (Figure 1G-I). Interestingly, most of the latter ones included cells that co-expressed both markers. For example, the clone shown in Figure $1 \mathrm{H}$ consists of four cells, two of which are positive for both anti-TTK and anti-HRP. The clone in Figure 1I consists of three cells, all of which coexpress antiHRP and AA142. Furthermore, the transcription factor Odd-skipped (anti-ODD), which normally specifically labels the MP1 neurons [25], is found to be co-expressed with AA142 in individually cultured clones $(\mathrm{n}=8$; not shown). Instability in the separation and/or maintenance of glial versus neuronal fate in cultured midline lineages is further supported by structural dynamics, as revealed by time-lapse recordings: during late stages of differentiation some cells changed their shape significantly and appeared to convert from glial to neuronal morphology (Additional file 1).

\section{Apoptosis}

Programmed cell death has been reported to occur in the embryonic CNS midline, especially in the glial lineages as revealed by marker gene expression in embryos deficient for apoptosis $[14,28,29]$. Accordingly, in such embryos 

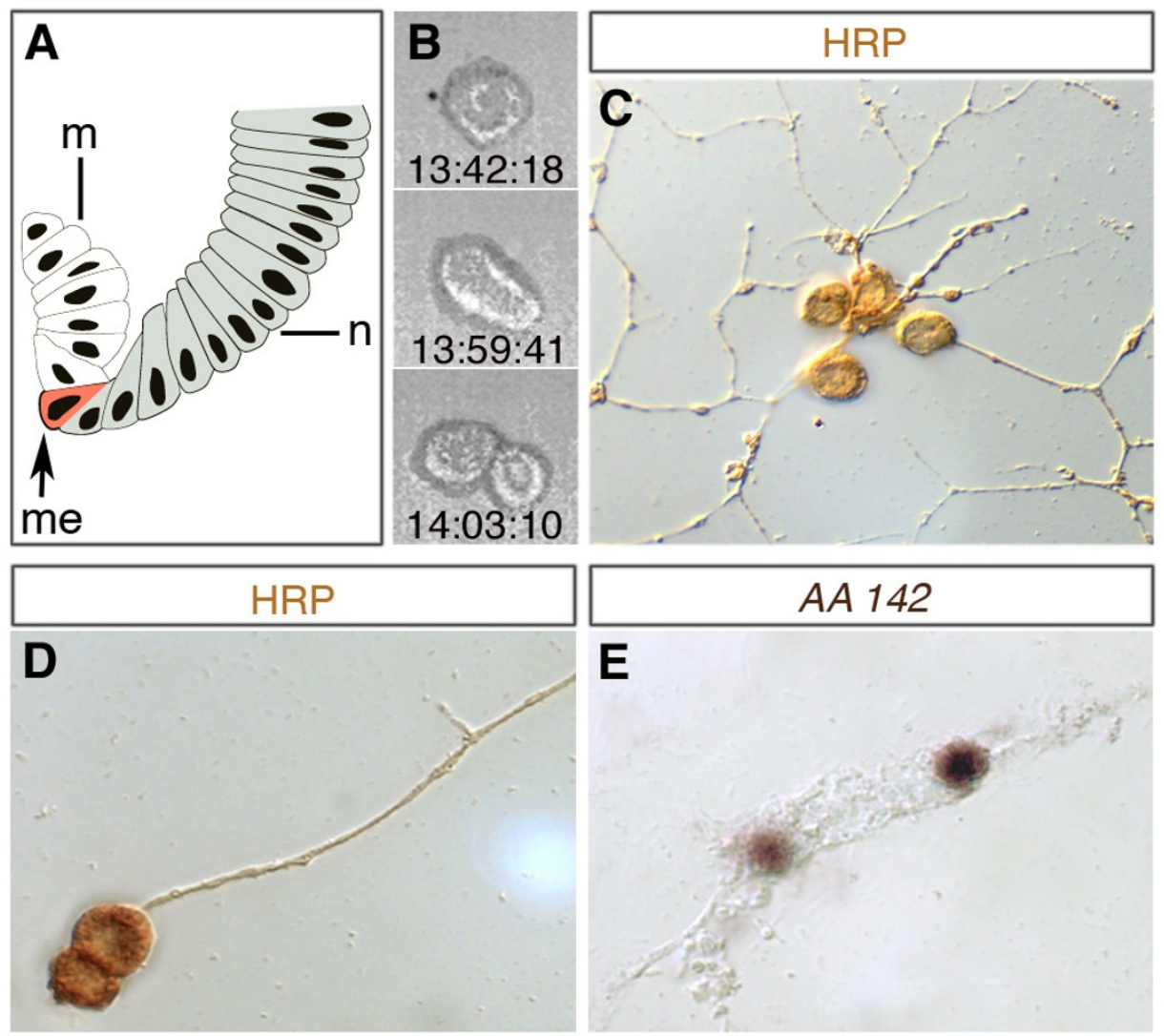

E
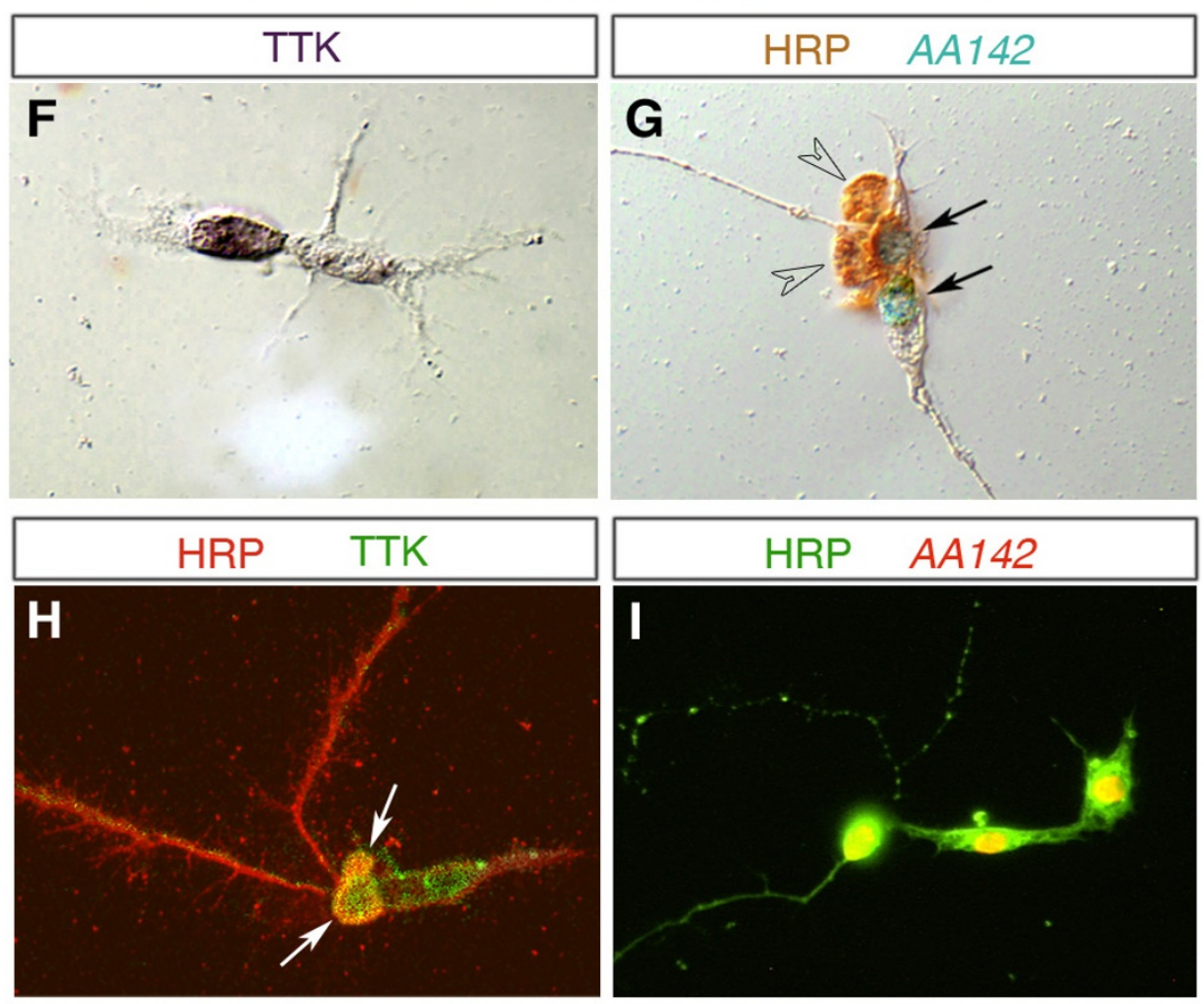

Figure I (see legend on next page) 
Figure I (see previous page)

Clones derived from individually cultured mesectodermal midline progenitors. (A) Schematic cross-section showing one side of the ventral half of an embryo at stage 7 (early gastrula stage; midline to the left, dorsal to the top). The row of mesectodermal midline progenitors (me; marked in red) is located at the ventral furrow between the neuroectoderm ( $\mathrm{n}$; grey) and the invaginated mesoderm ( $\mathrm{m}$; white). (B) Three frames from a time-lapse recording (real time is indicated) showing morphologically symmetrical division of an isolated midline progenitor. (C-I) Individually cultured midline progenitors give rise to clones that, based on morphological criteria, consist of neuronal (C,D) or glial cells (E,F) or a mixture of both (G-I). In (C,D) the entire lineage stains positive for the neuronal marker anti-horse radish peroxidase (HRP), and cells in (E) for the midline glia marker AAI42-lacZ (nuclear staining). In (F) only one of the two cells is labelled by the midline glia marker anti-Tramtrack (TTK). The clone in (G) comprises two anti-HRP-positive (brown; arrowheads) and two AAI42-positive cells (blue nuclei; arrows)). (H,I) Lineages including cells that co-express glial and neuronal markers. The clone in $(H)$ consists of four TTK (green) expressing cells, two of which (yellow; arrows) co-express HRP (red); the clone in (I) consists of three cells in which AAI42-lacZ (red) and HRP (green) are co-expressed (yellow). Markers applied in (C-I) are indicated. The size of midline progenitor cells is approximately $\mathrm{I} 2 \mu \mathrm{m}$ and of progeny cells 5 to $8 \mu \mathrm{m}$.

$(D f(3 L) H 99$, lacking the three key genes for the induction of apoptosis, reaper, hid, and grim [30]) midline glial cell clones labelled with DiI consisted of four to six cells at stage 17 (Janina Seibert and GMT, unpublished observations) instead of only two in the wild type. To examine whether the apoptotic cell fate is also expressed by midline clones growing in isolation, we first looked for morphological indications. In several cases (11 out of approximately 50 cases), between 2.5 and 14 hours after the progenitor was taken into culture (stage $7 / 8$ ), we observed individual progeny cells that rounded up and finally disintegrated into smaller particles. Morphological changes from first rounding until fragmentation of the cell (Figure 2A, B) take no more than 25 minutes as

Table I: Developmental properties of mesectodermal midline progenitors developing in vivo and in single cell cultures

\begin{tabular}{lcc}
\hline & In vivo* & In vitro \\
\hline Division pattern & & \\
Symmetric & $87 \%$ & $100 \%$ \\
Asymmetric & $13 \%$ & - \\
Clone size & & \\
2 cells & $74.3 \%$ & $37 \%$ \\
3 cells & $0.5 \%$ & $19 \%$ \\
4 cells & $7.6 \%$ & $44 \%$ \\
$5-8$ cells & $17.5 \%$ & - \\
Morphology & & \\
Neuronal & & \\
Glial & $84.5 \%$ & $78.4 \%$ \\
Mixed & $14.5 \%$ & $4.4 \%$ \\
Co-expression & $1 \%$ & $17.2 \%$ \\
HRP+TTK & & + \\
HRP+AAI42 & & + \\
ODD+AAI42 & - & + \\
Cell death & - & + \\
\hline
\end{tabular}

*In vivo data according to [22]. †For number of cases (n) see text. revealed by time-lapse video microscopy (Additional files 1 and 2). The occurrence of apoptosis in some of the cultured midline clones is further indicated by TUNEL-staining (Figure 2C, D). Thus, midline clones grown in isolation do express the apoptotic cell fate. However, our data do not allow drawing conclusions about the numbers and identities of the dying cells in culture.

Taken together, cells of the mesectoderm isolated at the pre-mitotic gastrula stage and grown in vitro exhibit some general characteristics of CNS midline progenitors. They divide symmetrically and give rise to progeny cells that express morphological characteristics of neuronal and glial cells or undergo programmed cell death. However, the distribution of clone sizes, the structural dynamics and (mis)expression of molecular markers indicate that their differentiation significantly differs from midline lineages developing in situ (summarized in Table 1). This suggests that midline cells are not dedicated to a particular fate at the precursor stage (stage 7), and are unable to generate a specific lineage autonomously. Instead, inductive signals appear to be required for the specification of the various midline cell types and/or maintenance of their fate.

\section{Development of progenitors from the ventral neuroectoderm in single cell culture}

To analyse the developmental properties of isolated cells from the neuroectoderm, cells were removed from the ventral neurogenic region at the early gastrula stage (stage $7 / 8$ ), prior to the onset of postblastodermal mitoses and to the delamination of NBs. Individual cells were immediately transferred to the culture medium and grown in vitro for up to 20 hours. Due to release from lateral inhibition, neuroectodermal cells grown in isolation produce neural clones exclusively [31]. 

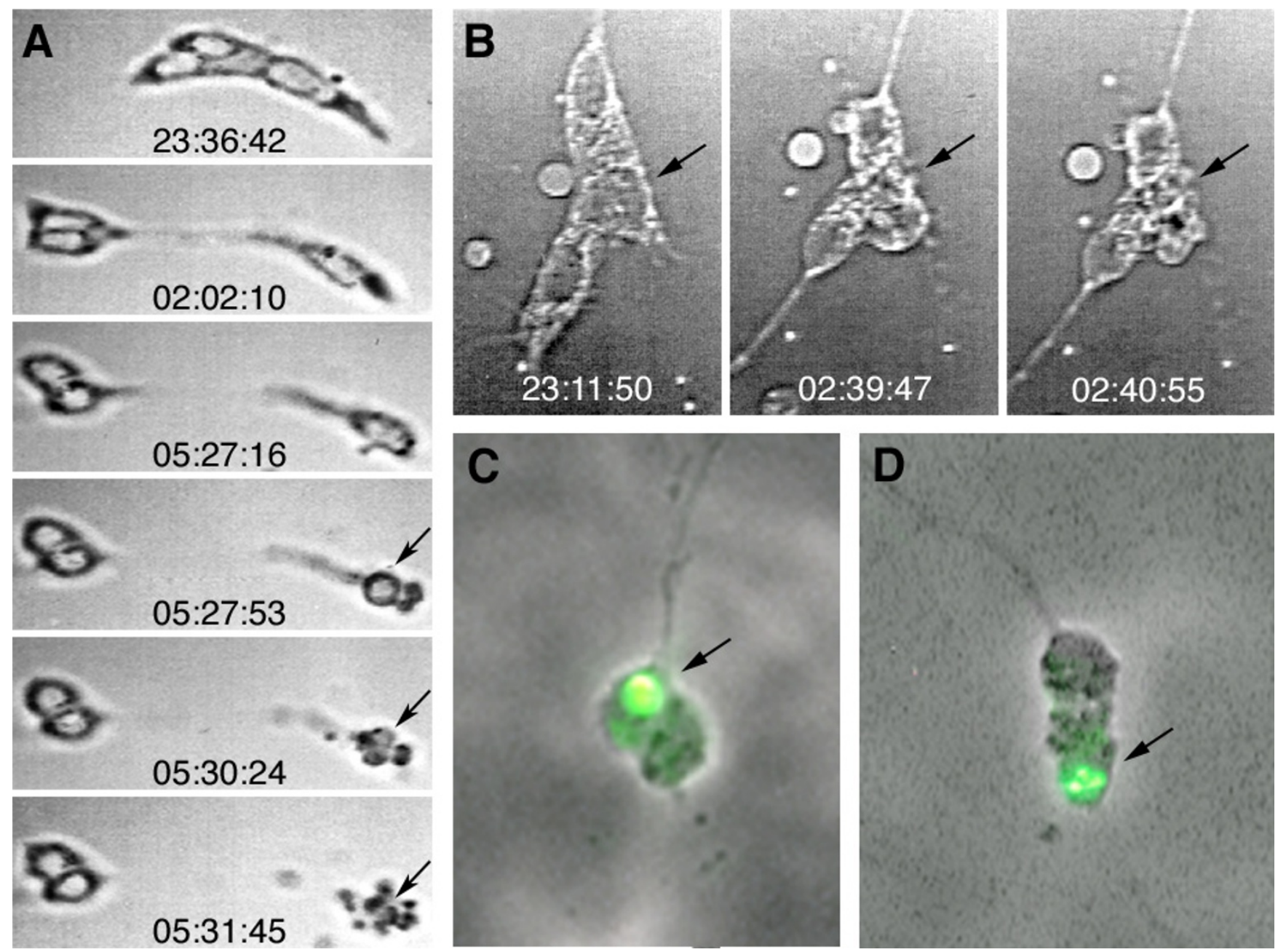

Figure 2

Programmed cell death occurring in individually cultured midline lineages. (A,B) Frames from time-lapse recordings (real time is indicated) of two developing midline clones (see Additional files $\mathrm{I}$ and 2 for the corresponding movies). In both clones one out of three cells disintegrates into smaller particles within a short period of time (arrows). The cell in (A) moves apart from its siblings before undergoing apoptosis. Migration over such distances in neural cell cultures is normally only performed by glial cells. (C,D) Midline clones in which apoptosis of one cell is indicated by TUNEL staining (arrow). Cell sizes correspond to 5 to $8 \mu \mathrm{m}$.

\section{Division patterns}

Sizes of clones produced by the isolated neuroectodermal progenitors varied between 2 and more than 20 cells (exact counting of cell numbers is difficult in large clones). This is true for cultured clones derived from the ventral half, as well as those derived from the dorsal half of the neuroectoderm. The distribution of clone sizes corresponds to the situation in situ (Additional file 3). Also, the mode and timing of mitoses of the cultured progenitor cells correspond to the behaviour of NBs in situ (Figure 3; Additional file 4). Generally, they divide asymmetrically in a stem cell mode, budding off smaller daughter cells (GMCs), which divide one more time symmetrically. Cell cycles of GMCs are significantly longer than those of the NBs.

\section{Differentiation}

Most of the clones consist of neurons exclusively, as judged by morphological criteria (Figure 4A). Some of the clones comprise glial cells in addition to neurons as confirmed by the expression of Repo (Figure 4B), a general marker for lateral glia cells [32]. We also observed expression of markers that are specific for smaller subsets of cells. For example, within some of the cultured clones individual cells express M84/P101-lacZ (Figure 4C) or MZ97-GFP (Figure 4D), which are specific to subsets of glial cells in the embryo, like the subperineurial glia [33]. 

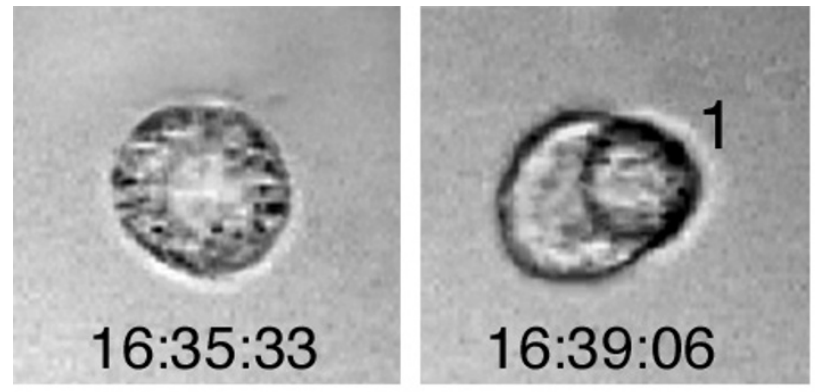

in vitro
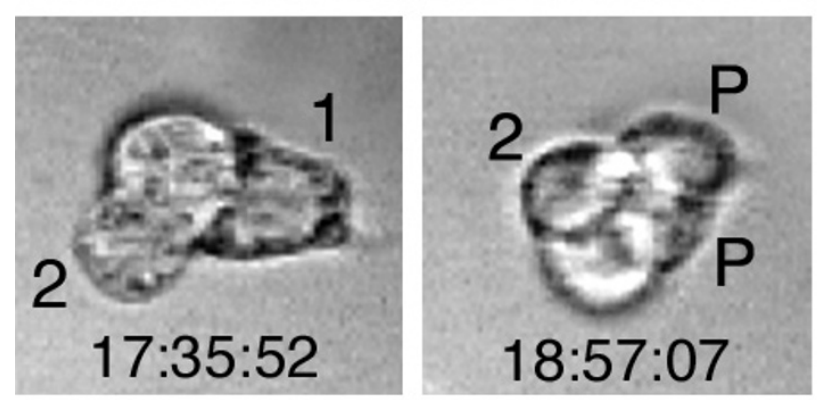

$16: 39$

(4h $30 \mathrm{~min}$

NB GMC P

$A E L)$
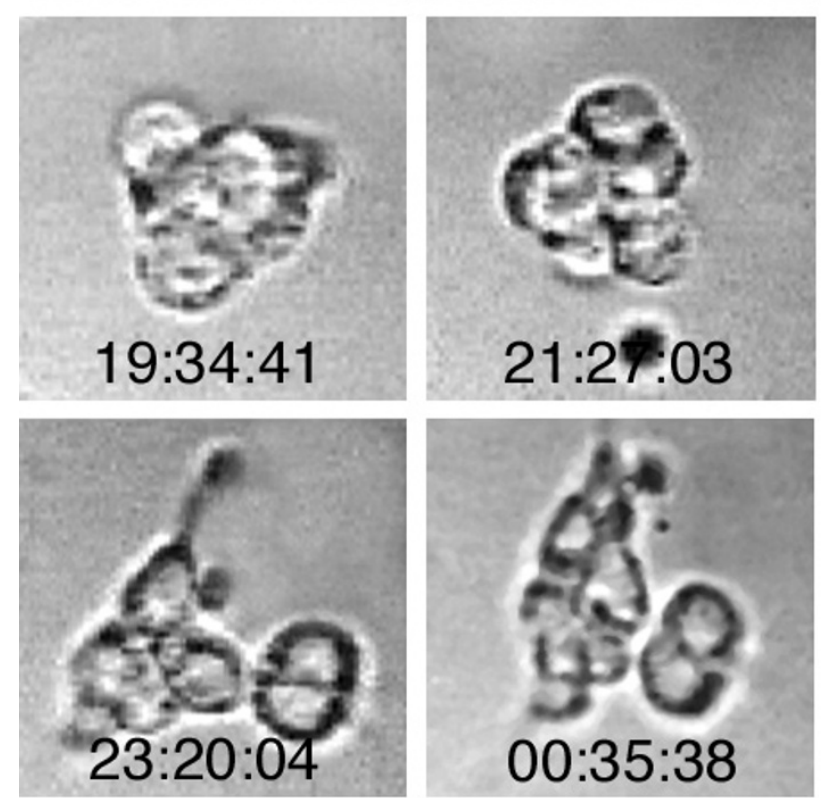

17:35

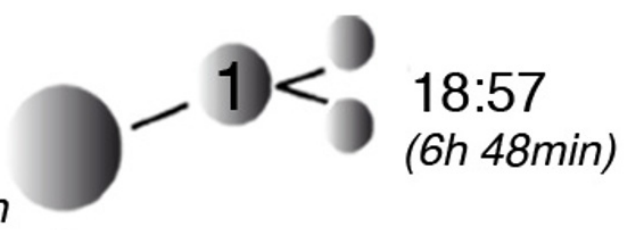

(5h 26min)
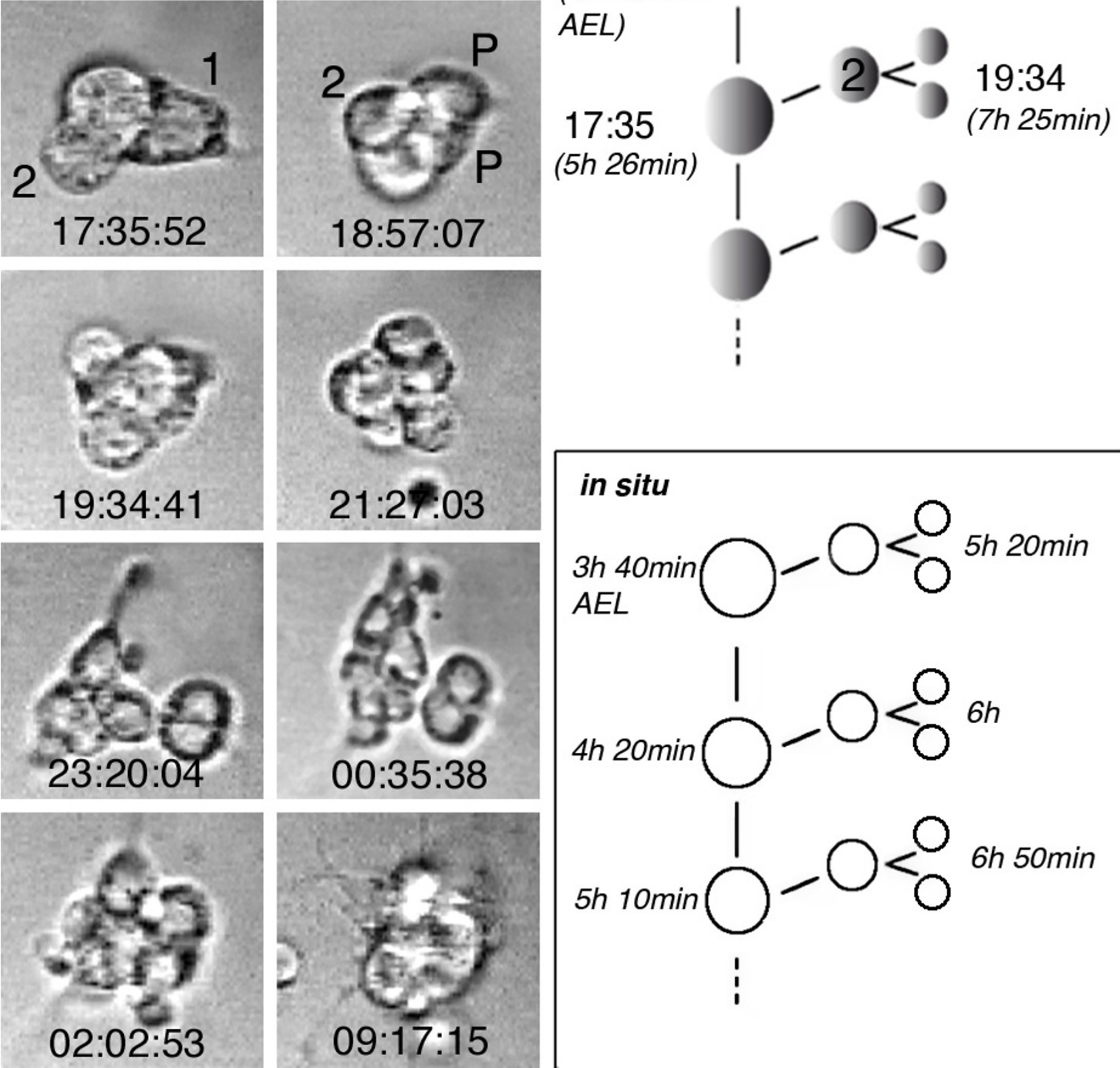

Figure 3 (see legend on next page) 
Figure 3 (see previous page)

Division pattern of an individually cultured neuroectodermal progenitor cell. Left panel: selected frames from timelapse recordings (real time is indicated) of a developing neuroectodermal progenitor cell (see Additional file 4 for the corresponding movie). Isolated neuroectodermal cells show a stem cell mode of division, which is typical for neuroblasts (NB). With each of their asymmetric divisions they self renew and bud off a smaller daughter cell (ganglion mother cell (GMC); the numbers $I$ and 2, indicate the first two GMCs), which typically divides one more time into two postmitotic progeny (P). The size of the NB is approximately $10 \mu \mathrm{m}$ and of postmitotic progeny cells 5 to $6 \mu \mathrm{m}$. Right panel: the time points when the first divisions took place in this particular lineage (grown at $22^{\circ} \mathrm{C}$ ) are indicated at the top (compare left panel). The respective times after egg laying (AEL) are indicated in brackets. Note that the cell cycle of GMCs is significantly longer than that of the NB. The lower scheme shows for comparison the timing (at $25^{\circ} \mathrm{C}$ ) of the first mitotic cycles of NBs and GMCs as observed in situ (according to Hartenstein et al. [69]).

While neuronal progeny stay in a dense cluster, glial cells sometimes move away from the cluster (Figure 4D), which also resembles the situation in situ. Several of the individually cultured neuroectodermal progenitor cells produced clones staining positive for Eagle (Figure 4E), expression of which is restricted to four lineages in the embryo (those of NBs 2-4, 3-3, 6-4 and 7-3 [34]). Furthermore, a few clones included one to two cells expressing the neurotransmitter serotonin (Figure 4F). In the embryo, serotonergic neurons derive exclusively from NB7-3; the late embryonic NB7-3 lineage consists of four cells, two of which express serotonin (as is the case for the clone shown in Figure 4F).

Programmed cell death is part of the normal developmental programme of most of the NB lineages [35]. Accordingly, using anti-activated Caspase 3 (Figure 4G) or TUNEL staining (Figure $4 \mathrm{H}$ ), we detected apoptosis of individual neuronal progeny cells in some clones of cultured neuroectodermal progenitor cells.

\section{Cultured progenitors generate specific types of lineages depending on their site of origin within the neuroectoderm}

In the embryo each NB occupies a specific position in the NB layer corresponding to its site of delamination from the ectoderm (Figure 5A', A"), and it produces a specific lineage $[1,3-5]$. In order to test whether precursors already become firmly committed for specific NB fates in the neuroectoderm, and whether they are able to express their specific fate autonomously, we cultured single cells, which were taken (at stage 7) from well-defined dorsoventral positions in the abdominal neuroectoderm. Cells were removed from the neuroectoderm at a certain distance from the midline ( 1 to 4,5 to 9 , and 10 to 15 cell diameters/rows; the total dorsoventral dimension of the neuroectoderm was approximately 15 cell diameters; Figure $\left.5 \mathrm{~A}^{\prime \prime}\right)$. They were individually grown in culture for up to 20 hours, and their lineages stained against cell specific markers.

First, we analyzed the ability of cultured neuroectodermal progenitor cells to produce glial progeny by staining with the glial specific anti-Repo antibody. Out of 106 clones deriving from ventral progenitor cells of neuroectodermal rows 1 to $4,27(26 \%)$ included glial cells in addition to neurons. The number of glia in these clones varied between one and four cells (as some of the glia stay in close association with other components of their lineages, and due to their flat shape assessment of their exact number is often difficult). In the embryo the only glial progenitor delaminating from this region in abdominal segments is the neuroglioblast NB1-1, which produces three glial cells in addition to neurons (see below). The rather high frequency of this type of clone obtained in culture $(26 \%)$ is probably due to the fact that cells were removed from the neuroectoderm at an early stage, when proneural clusters for early delaminating NBs (S1, S2) $[1,3]$ are in place while those for late delaminating NBs (S3 to S5) may still have to be established (see also distribution of clonal frequencies below). In the embryo only four out of about nine ventral NBs delaminate during S1/ S2, and NB1-1 is one of them (corresponding to 25\%). Cultured progenitor cells deriving from the most dorsal sector of the neuroectoderm (rows 10 to $15 ; \mathrm{n}=332$ ) gave rise to clones that stained positive for Repo in a higher number of cases (37\%; 122 clones). Of these Repo-positive clones, 104 (85\%) were mixed clones comprising 1 to 6 glial cells in addition to neurons (Figure 5F), whereas 18 clones (15\%) consisted of glial cells exclusively (data not shown). These purely glial clones generally consisted of either only two cells (nine clones) or eight cells (six clones). Thus, the percentage of cultured clones comprising glial cells depends on whether precursors were taken from ventral or dorsal sites of the neuroectoderm. This resembles the situation in vivo: in the embryo, almost all glial progenitor cells (except abdominal NB1-1 and thoracic NB2-2) derive from the most dorsal sector of the neuroectoderm (rows 10 to 15), among them four neuroglioblasts producing mixed lineages (NB1-3, NB2-5, NB56, NB7-4) and two glioblasts (NB6-4a, GP). The abdominal NB6-4a glioblast gives rise to only two glial cells, and the GP produces seven to nine glial progeny $[3,4]$. 

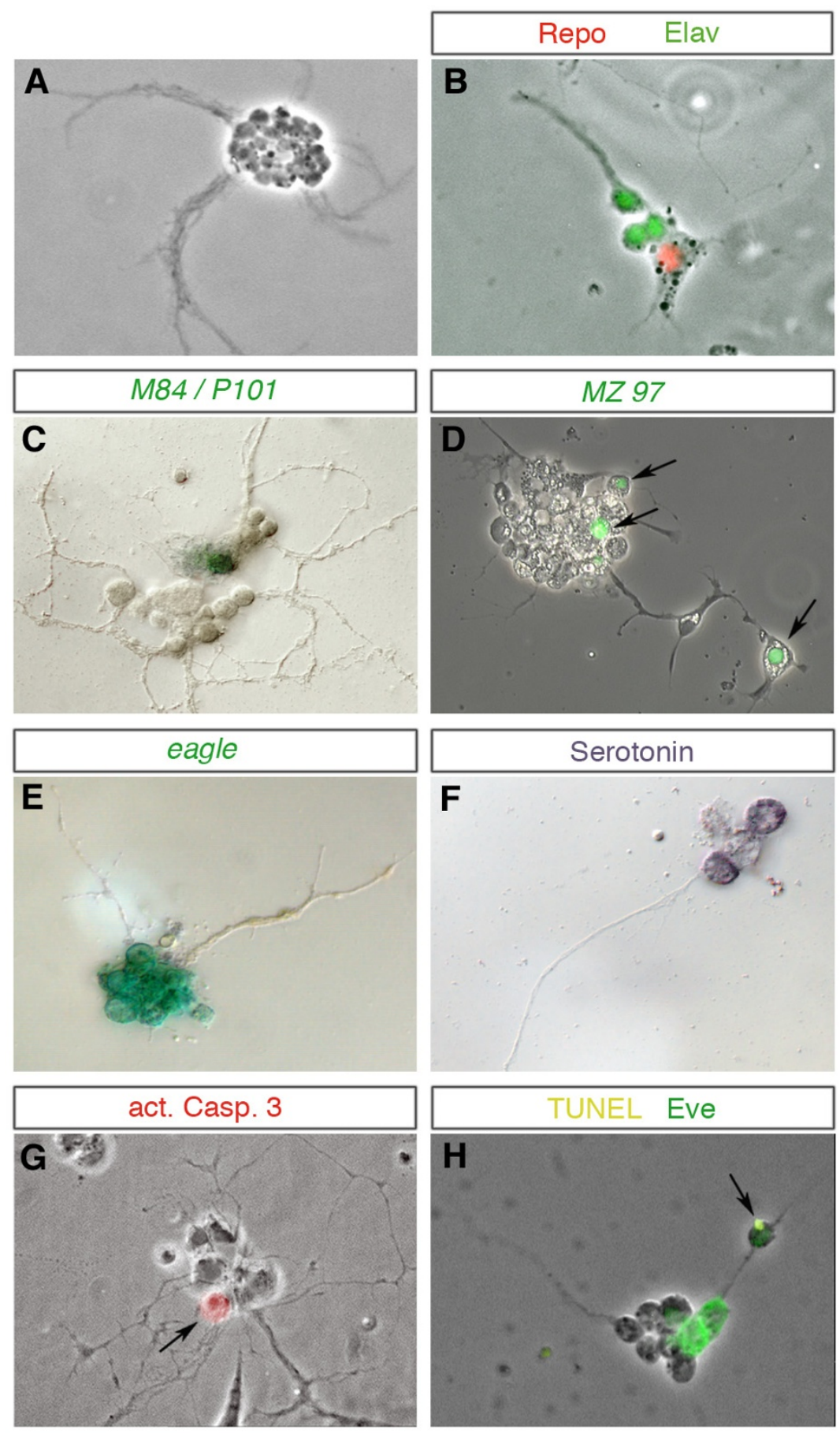

\section{Figure 4}

Differentiation of individually cultured neuroectodermal progenitor cells. (A-H) Cultured neuroectodermal progenitor cells produce between 2 and more than 20 neural progeny cells. Neurons show small round cell bodies and develop long fibre projections that sometimes fasciculate. Glia exhibit flat cytoplasmic protrusions with irregular shape. Besides general markers for neurons or glia (B) (anti-Elav, green; anti-Repo, red), some clones express markers characteristic for particular subsets of neurons ((F) anti-serotonin; $(H)$ anti-Eve), for subsets of glial cells ((C) M84/PI0I-lacZ; (D) Mz97-GFP, arrows) or for particular lineages $((\mathrm{E})$ eagle-lacZ). Some progeny cells undergo programmed cell death as revealed by anti-activated Caspase $3(\mathrm{G}$, arrow) or TUNEL staining $(\mathrm{H})$ (see yellow spot (arrow) in distant cell of clone double-stained against Eve). Markers applied in (B-H) are indicated. The sizes of postmitotic progeny cells correspond to 5 to $6 \mu \mathrm{m}$. 

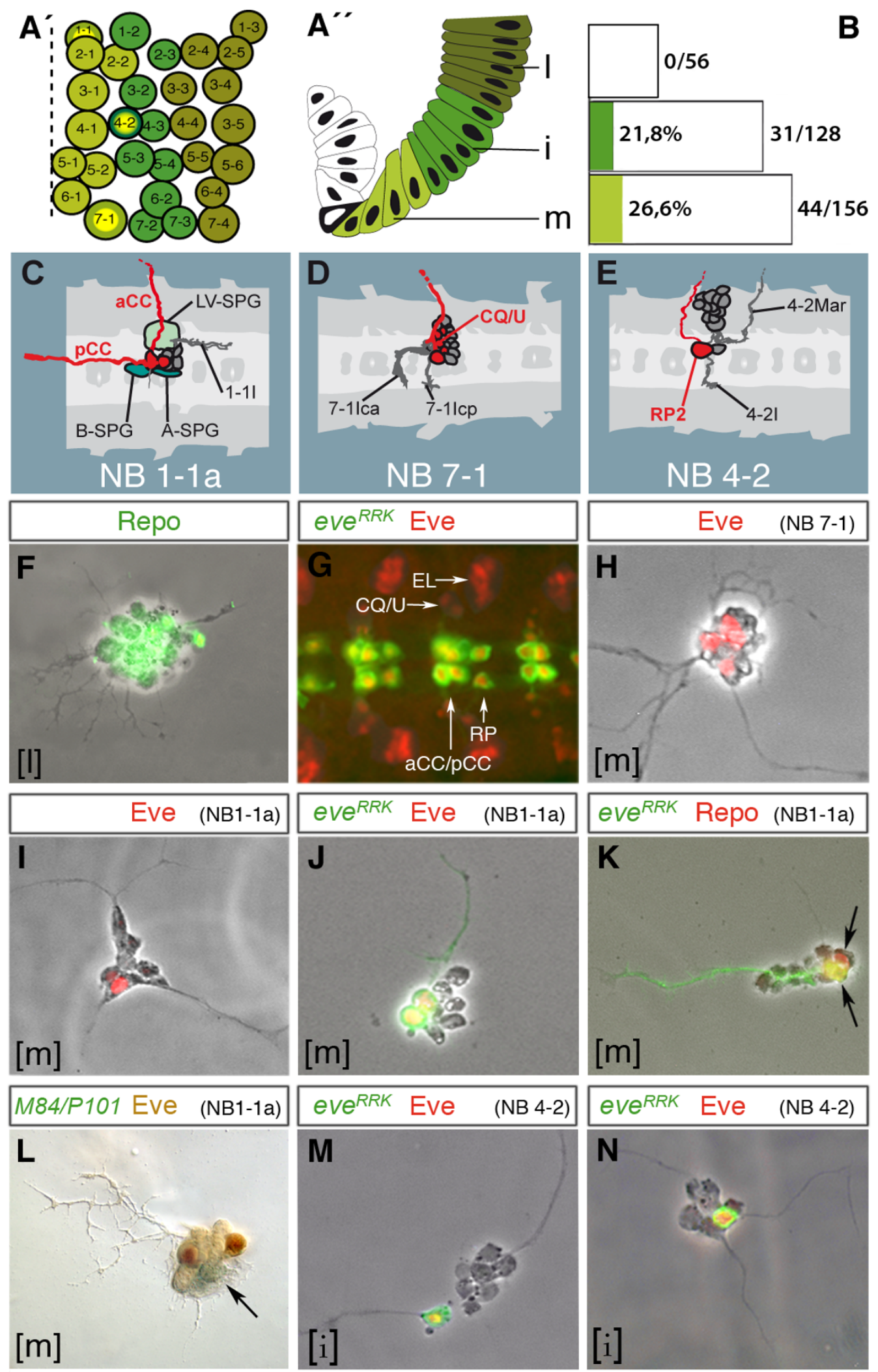

Figure 5 (see legend on next page) 
Figure 5 (see previous page)

Early specification and developmental autonomy of neuroectodermal progenitor cells. (A') Neuroblast map of a truncal hemisegment at stage 10 (based on [I]). Anterior to the top; broken line marks midline. Medial (light green), intermediate (medium green) and lateral neuroblasts (dark green) delaminate from particular dorsoventral regions of the neuroectoderm as indicated by corresponding colour code in A". (A") Stage 7 neuroectoderm: $m$ (medial, rows I to 4), i (intermediate, rows 5 to 9), I, (lateral, rows 10 to I5). Dorsal to the top, midline to the left (mesoderm, white; mesectoderm, black). (B) Proportion of cultured lineages comprising eve-GFP expressing cells. Progenitors derive from specific neuroectodermal domains (as indicated by colour code; compare A") of the eve-Gal4RRK strain. (C-E) Semi-schematic presentation of embryonic lineages (horizontal views; anterior to the left; according to [3]), which include eve-expressing cells (marked in red; see text for further description). Progenitor cells NBI-la (abdominal), NB7-I, and NB4-2 are highlighted with yellow spots in (A'). (F) Clone derived from a cultured lateral neuroectodermal progenitor (I), comprising glia in addition to neurons. (G) Ventral nerve cord (horizontal view; anterior to the left) of an eve-Gal4RRK/UAS-mCD8::GFP stage 15 embryo double-stained against CD8 (green; $\mathrm{aCC} / \mathrm{pCC}, \mathrm{RP2}$ ) and Eve (red; lateral cluster (EL), CQ/U motoneurons, and co-expression in aCC, PCC, and RP2 (yellow nuclei)). (H-N) Clones derived from medial $(\mathrm{m})$ or intermediate (i) neuroectodermal progenitors of wild-type $(\mathrm{H}, \mathrm{I})$, eveGal4RRK/UAS-mCD8::GFP (J,K,M,N) or M84/PIOI-lacZ embryos (L) as indicated. $(\mathbf{H}, \mathbf{I})$ Cones including four to five $(\mathrm{H})$ and two (I) Eve-expressing cells, respectively. (J) Clone including two cells co-expressing CD8-GFP and Eve. (K) Clone including two Repo-positive glial cells (arrows) and two Eve-positive neurons (cell bodies out of focus)). (L) Clone including two Eveexpressing neurons (brown) and one to two lacZ-expressing cells with flat glia-like shape (green, arrow). (M,N) Clones including one prominent cell double stained against CD8 (green) and Eve (red). Cell sizes in (F,H-N) correspond to 5 to $6 \mu$ m. Markers and putative identities of cultured lineages are indicated on top of each picture, and their site of origin in the neuroectoderm at the bottom.

Second, we analyzed lineages that give rise to cells expressing the marker even-skipped (eve). NB1-1 and NB7-1 belong to the subset of medial NBs (Figure 5A, C, D) and delaminate from the most ventral part of the neuroectoderm (one to three cell diameters apart from the ventral midline according to DiI labelling [3]). NB4-2 belongs to the subset of intermediate NBs and delaminates from a ventrolateral site of the neuroectoderm (five to nine cell diameters apart from the ventral midline; Figure 5A, E). In the embryo, abdominal NB1-1 produces a clone consisting of three subperineurial glial cells, one motoneuron (aCC), one interneuron projecting anteriorly (pCC), and a small cluster of four to six interneurons forming a fascicle projecting posteriorly (Figure 5C) [36]. aCC and pCC express eve [37]. The NB7-1 lineage (Figure 5D) consists of 16 to 22 neurons, including 5 eve-expressing cells (CQ/U neurons $[3,37,38])$. NB4-2 gives rise to 8 to 14 interneurons and two motoneurons, one of which (RP2) expresses eve $[3,38]$ (Figure 5E). The pattern of Eve-expressing cells in the ventral nerve cord of a stage 15 embryo is shown in Figure 5G.

When culturing cells from the ventral-most neuroectoderm (rows 1 to 4 ) and staining with an anti-Eve antibody (n = 532), we obtained 199 clones $(37.4 \%)$ with eveexpressing progeny. Of these clones, 33\% included 3 to 7 (Figure 5H) and 67\% included 1 to 2 Eve-positive cells (Figure 5I). With regard to their site of origin and numbers of eve-expressing progeny, these clones appear to reflect characteristics of the NB1-1 and NB7-1, respectively.

To test this in more detail, we used the line eve-Gal4RRK [39], which expresses Gal4 exclusively in the NB1-1- derived aCC and pCC and in the NB4-2-derived RP2 motoneuron [40]. We used this line to drive expression of green fluorescent protein (GFP; UAS-mCD8::GFP [41]) in these cells (Figure 5G). Embryos carrying these constructs were used as donors for neuroectodermal cells. Out of 165 clones obtained from individually cultured neuroectodermal cells of rows 1 to 4, 44 (26.6\%; Figure 5B) included 2 cells $(79.5 \%$ of the 44 clones; Figure $5 \mathrm{~J}), 1$ cell $(11.5 \%)$, and 3 cells ( $9 \%)$ expressing $e v e^{R R K}$; as reflected by a prominent axonal fascicle, these cells are neurons. The total number of cells within these clones generally varied between 8 and 14. In some clones eve-expression in these cells was confirmed by double staining with the anti-Eve antibody (Figure 5J). Furthermore, we double-stained 11 of the mCD8::GFP-positive clones from rows 1 to 4 against the glial marker Repo and found two Repo-positive cells in six (Figure 5K), and one Repo-positive cell in one of these clones. We also cultured single neuroectodermal cells of rows 1 to 4 from the enhancer trap strain $\mathrm{M} 84 / \mathrm{P} 101$ [42]. This line expresses lacZ specifically in a set of subperineurial glial cells, including those produced by abdominal NB1-1 [36]. Figure 5L shows a clone double-stained against Eve and $\beta$-galactosidase that includes two cells expressing Eve and one to two cells expressing $\beta$ galactosidase and exhibiting glial morphology. Since abdominal NB1-1 is the only precursor generating eveexpressing cells in addition to glia, the expression of both markers in vitro is indicative for the NB1-1 fate (Figure $5 C)$.

Finally, 31 out of 142 clones (21.8\%; Figure 5B) produced by progenitors from neuroectodermal rows 5 to 9 included $1(93.5 \%$ of the 31 clones; Figure $5 \mathrm{M}, \mathrm{N})$ or 2 
$(6,5 \%) e v e^{R R K}$-positive cells in addition to 6 to 12 eve-negative cells. This reflects characteristics of the NB4-2 lineage in situ (Figure 5E). Furthermore, the eve-positive cell develops a prominent fibre projecting separate from other clonal fibres. Finally, this cell tends to move a short distance apart from the clonal cell cluster (Figure 5M), as is the case for RP2 in the embryonic NB4-2 lineage (Figure $5 \mathrm{E})$. In contrast, none of the progenitors taken from the most dorsal site of the neuroectoderm (rows 10 to $15 ; \mathrm{n}=$ 56; Figure 5B) gave rise to progeny expressing the marker eve $e^{R K}$, as is the case in situ.

Taken together, these data indicate that presumptive NBs have already acquired a high degree of commitment in the neuroectoderm, and are able to cell-autonomously express specific characteristics of their lineages when grown in primary culture.

\section{Discussion \\ Culturing individual neural precursors of defined spatial and temporal origin}

Drosophila primary cultures have been used for decades to investigate various aspects of neural development and function. The morphological, physiological and molecular characterization of primary neural cultures revealed that their developmental and physiological properties mirror a great number of characteristics in the intact organism [31,43-57]. Since large numbers of cells from dissociated early embryos or a NB-enriched fraction of cells were cultured in most of these experiments, the sites of origin of the cells in the embryo and their precise developmental stage were not known. Under these conditions, comparisons of developmental capacities of specific types of precursors in situ and in vitro are very limited, if at all possible.

We have therefore established a means to remove progenitor cells from specific sites (as defined by morphological landmarks and the availability of a detailed fate map [58]) of precisely staged embryos and grow them individually in culture. So far, we have used this method to study the intrinsic component in the determination of neural versus epidermal cell fate as a function of the distribution of progenitor cells along the dorsoventral axis of the ectoderm [31], and to study the cell-autonomous component in the expression of ionic currents by neurons derived from CNS midline precursors [54]. In these experiments, however, we did not distinguish and compare between specific types of CNS lineages.

Here we studied in single cell cultures the development and composition of lineages generated by CNS midline precursors and by presumptive NBs taken at the early gastrula stage from specific dorsoventral domains of the truncal neuroectoderm. By comparison with the previously described CNS lineages in situ [3-5,22], this approach allows cell-autonomous properties versus the requirements for extrinsic signals during lineage development of specific subpopulations of CNS progenitor cells to be uncovered for the first time.

\section{Non-cell-autonomous control of proliferation and cell fate determination within CNS midline lineages}

The mesectodermal midline cells are initially specified during the blastoderm stage by the master regulator gene single-minded (sim), which is required for subsequent development of all midline cells [59]. Transplantation experiments revealed that premitotic mesectodermal cells (early gastrula, stage 7) are firmly committed to form midline progenitors and to occupy/maintain a midline position in the developing CNS [11]. Individually cultured mesectodermal precursor cells exhibit cell-autonomous developmental capacities with regard to the expression of morphological characteristics of neuronal and glial cell fates, and to programmed cell death. Furthermore, as previously shown for midline neurons, the expression of voltage-gated potassium currents appears to be cell-autonomous [54]. These autonomous properties represent rather general characteristics that apply for the entire ventral midline primordium.

In contrast, the establishment of specific characteristics and diversity among midline lineages does not appear to be a cell-autonomous property of midline progenitors. The clones we obtained from individually cultured midline progenitors significantly differed from midline lineages in situ with regard to proliferation (clone size distribution, no asymmetric divisions) and the expression of molecular markers (co-expression of neuronal and glial markers). Thus, midline progenitors grown in isolation lose their ability to properly control their proliferation and clear definition and/or separation between neuronal and glial fate. This suggests that determination of specific aspects of their fate requires extrinsic inductive signals. A possible requirement for signalling among components of different midline lineages has been discussed previously as a means for matching variable numbers of midline progenitors (six to eight cells per segment) with the final population of postmitotic progeny cells [22]. Bossing and Brand [23] have shown that cell fates within the CNS midline are determined after the precursors divide by Wingless and Hedgehog signalling acting on their daughter cells. Furthermore, Wheeler et al. [15] reported recently that, after the stage 8 division, Notch signalling promotes midline glia and $\mathrm{MNB}$ cell fate and is also required for asymmetric daughter cell fate in particular midline lineages. However, it is not clear as to how far these signals act among lineage-related and/or non-related progeny cells, and little is known about influences on midline precursor cell fate before they enter mitosis at stage 8 . In our exper- 
iments, individual pre-mitotic midline precursors have been removed from the embryo at stage 7 . Therefore, exchange of signals within their lineages should still be possible in culture, whereas those coming from other lineages would be lacking (the same is true for the NB lineages in culture; see below). The characteristics of the cultured clones reveal that cell autonomous properties of midline precursor cells and signalling among clonally related progeny cells are not sufficient for normal control of their development. This is indicative for the existence of inductive signals in the embryo that are acting early within the mesectoderm and/or coming from neighbouring primordia (neuroectoderm, mesoderm). The nature of these signals remains to be clarified.

\section{Development of presumptive neuroblasts shows a high degree of cell autonomy}

In the embryo each of the approximately $30 \mathrm{NBs}$ per truncal hemisegment expresses a characteristic set of molecular markers [1,37] and produces a unique cell lineage [35]. Superimposition of segment polarity and dorsoventral patterning gene activities in the neuroectoderm can explain how each descending NB acquires an individual fate (reviewed in $[6,7]$ ). Heterotopic and heterogenetic transplantation experiments have previously revealed a high degree of commitment of early neuroectodermal cells for ventral NB fates [11] and for segmental specificity $[10,60]$. Furthermore, heterochronic transplantations have shown that the specification of temporal subsets of NBs occurs under the control of stage-specific inductive signals acting in the neuroectoderm [9].

Our in vitro experiments indicate a high degree of cellautonomy of early neuroectodermal cells in generating specific types of lineages. As individually cultured progenitor cells were devoid of signals coming from other primordia (neuroectoderm, mesoderm) or other lineages, their early exposure to positional cues within the neuroectoderm appears to be sufficient for specification and subsequent development of characteristic features of particular NB lineages, like NB1-1. Accordingly, NBs cultured after their delamination in cell suspensions of approximately 5-hour-old embryos develop lineages showing the same temporal transcription factor expression windows (Hunchback $\rightarrow$ Pou-homeodomain proteins 1 and $2 \rightarrow$ Castor $\rightarrow$ Grainyhead) as in the embryo [44]. On the other hand, delaminated NBs require extrinsic signals from the overlying neuroectoderm during interphase to regulate spindle position and apical protein localization [12]. However, since interphase protein localization appears to be unnecessary for subsequent protein localization and unequal NB cytokinesis at mitosis [43], individual NBs in vitro divide asymmetrically in a normal stem cell mode, producing a chain of progeny cells that inherit differential cell fates.

\section{Conclusion}

We have analyzed the development and composition of lineages generated by individually cultured mesectodermal CNS midline precursors, and by presumptive NBs taken from specific dorsoventral domains of the truncal neuroectoderm. Comparison of the clones generated by neural precursors of defined spatial and temporal origin in vitro with the well-described characteristics of the lineages in situ uncovers cell-autonomous properties versus the requirements for extrinsic signals during development of the respective progenitor cells. Our experiments demonstrate that the isolated cells express characteristics of the progenitor type appropriate to their site of origin in the Drosophila embryo. However, the two sets of CNS progenitor cells exhibit different degrees of cell-fate commitment at the pre-mitotic and pre-delamination stage. Presumptive NBs, once specified by positional information in the neuroectoderm, show a higher degree of autonomy regarding the generation of their lineages as compared to mesectodermal midline progenitors.

\section{Materials and methods Drosophila strains}

We used Oregon $\mathrm{R}$ wild-type flies and the following enhancer trap lacZ, Gal4 and UAS lines: M84, P101, AA142 [42]; eve-Gal4RRK [39,40]; repo-Gal4 [61]; eagle-Gal4 (MZ360) [62]; UAS-mCD8::green fluorescent protein (UAS$m C D 8:: G F P$ [41]; Bloomington Stock B-\#5130), and UASlacZ [63].

\section{Single cell cultures Culture medium}

We used Schneiders medium for culture medium [64-66]. Non heat-inactivated foetal calf serum was added to $10 \%$. After addition of serum, the medium was kept for 3 days at $25^{\circ} \mathrm{C}$, then insulin $(200 \mathrm{ng} / \mathrm{ml})$ was added, and $\mathrm{pH}$ adjusted to 6.8 to 6.9 .

Isolation and culturing of individual neural progenitor cells Embryos at the blastoderm stage were washed in 70\% ethanol, dechorionated, mounted in an appropriate orientation on a cover-slip coated with glue, desiccated and covered with fluocarbon oil. Embryos were selected as donors at about stage 7 to 8 (stages according to [67]), when the midline precursors are clearly distinguishable. A capillary (provided with an approximately $45^{\circ}$ bevel and an inner tip diameter of 12 to $13 \mu \mathrm{m}$ for the removal of midline progenitors, and a 10 to $12 \mu \mathrm{m}$ diameter for the removal of neuroectodermal progenitor cells) was introduced into the embryo along the longitudinal axis, and three to six cells from the ventral midline or from specific dorsoventral cell rows of the neuroectoderm (as counted from the ventral midline) were removed. Cells were cultured as previously described [31]. Briefly, a single cell was released from the capillary and placed centrally onto a 
clean, sterile glass coverslip in a drop (20 to $30 \mu \mathrm{l})$ of sterile culture medium. In cases when more than one cell was released into the medium, they were deposited individually with large separation distances in order to prevent cell interactions. The cover slip (greased at its fringes) was then sealed onto a small, sterilized culture vessel [68]. The vessel was turned upside down, placed over the coverslip and pressed down to seal the chamber tightly. The drop of medium adhered to both sides to form a column in the centre of the chamber. Cultures were kept for 16 to $20 \mathrm{~h}$ in the dark in an incubator at $26^{\circ} \mathrm{C}$, or their development was continuously traced at room temperature (approximately $22^{\circ} \mathrm{C}$ ) by time-lapse recordings as previously described [31].

\section{Staining procedures and antibodies}

Cells were fixed and stained as previously described [31]. Cells were stained for $\beta$-galactosidase expression with rabbit-anti- $\beta$ gal antibodies (1:5,000; Cappel-Promega, Mannheim, Germany) or using X-Gal staining. Apoptotic cells were detected by TUNEL staining (in situ Cell Death Detection kit, Roche Diagnostics, Mannheim, Germany) or by antibody staining against rabbit anti-human activated Caspase 3 (1:50; Cell Signalling Technology, Danvers, MA, USA). Additionally, the following primary antibodies were used: mouse anti-Even-skipped (1:2; Developmental Studies Hybridoma Bank, University of Iowa, IA, USA), rabbit anti-GFP (1: 250; Torrey Pines Biolabs, East Orange, NY, USA), mouse anti-HRP (1:20; Dako, Hamburg, Germany), rabbit anti-Odd-skipped (1:5,000; James Skeath, Washington University School of Medicine, St Louis, MO, USA), rabbit anti-Repo (1:200) [32], rat anti-serotonin (1:50; Accurate, Westbury, NY, USA), and rat anti-TTK $(1: 1,000)$ [26]. The secondary antibodies used were: anti-rat-fluorescein isothiocyanate (FITC), anti rabbit-FITC, anti mouse-Cy3, anti mouse-alk. Phosphatase, anti mouse-HRP, and anti rabbit-HRP (1:300; all Jackson ImmunoResearch, Suffolk, UK). For DAB stainings, the ABC kit from Vectastain (Burlingame, CA, USA was used.

Colour images were made using a Zeiss Axioskop 2 microscope.

\section{Competing interests}

The authors declare that they have no competing interests.

\section{Authors' contributions}

KL carried out the cell culture studies and created the figures. GMT conceived of the study and wrote the manuscript.

\section{Additional material}

\section{Additional file 1}

Differentiation and cell death in a cultured midline lineage. Timelapse movie showing a midline lineage developing in vitro. Three postmitotic progeny cells exhibiting glial morphology are generated. One of these cells undergoes cell death (disintegration into several particles), whereas the other two convert their shape to assume neuronal morphologies (cell bodies round up and form long fibre projections). Real time is indicated at the bottom. Selected frames are shown in Figure 2B. Click here for file

[http://www.biomedcentral.com/content/supplementary/17498104-4-30-S1.mov]

\section{Additional file 2}

Differentiation and cell death in a cultured midline lineage. Timelapse movie showing a midline lineage developing in vitro. Two divisions lead to three progeny cells exhibiting glial morphology. One of these cells moves apart from the others and undergoes cell death (disintegration into several particles). Real time is indicated at the bottom. Selected frames are shown in Figure 2A.

Click here for file

[http://www.biomedcentral.com/content/supplementary/17498104-4-30-S2.mov]

\section{Additional file 3}

Comparison of clone sizes obtained in vitro and in situ from progenitors of the ventral and dorsal half of the neuroectoderm. Comparison of clone sizes obtained in vitro and in situ from progenitors of the ventral and dorsal half of the neuroectoderm.

Click here for file

[http://www.biomedcentral.com/content/supplementary/17498104-4-30-S3.doc]

\section{Additional file 4}

Development of an individually cultured neuroectodermal progenitor cell. Time-lapse movie showing the development of a cultured progenitor cell that originated from the most ventral domain of the neuroectoderm. The generation of the first two ganglion mother cells (GMC1 and GMC2) by asymmetric divisions of the neuroblast and the symmetric division of GMC1 (taking place after GMC2 is born) into two postmitotic progeny cells $(P)$ are indicated in the film. Assignment of further divisions is difficult due to the dense, three-dimensional arrangement of progeny cells. Note that during maturation of the clone (after approximately 23:15) a prominent pair of equally sized cells (which seem to be the two progeny of GMC1) moves a short distance apart from the cell cluster (along a fibre bundle) to later join the cluster again. Real time is indicated at the bottom. Selected frames and a schematic of the early divisions are shown in Figure 3.

Click here for file

[http://www.biomedcentral.com/content/supplementary/17498104-4-30-S4.mov]

\section{Acknowledgements}

We would like to thank Ana Rogulja-Ortmann for critically reading the manuscript, and Christof Rickert for his help in designing the figures and his comments on the manuscript. We are very grateful to Stephen Crews, Christian Klämbt, Doris Kretzschmar, Andreas Prokop, Jim Skeath, James Jaynes, and the Bloomington Stock Center for fly strains and antibodies. 
This work was supported by a grant from the Deutsche Forschungsgemeinschaft to GMT.

\section{References}

I. Doe CQ: Molecular markers for identified neuroblasts and ganglion mother cells in the Drosophila central nervous system. Development 1992, I 16:855-863.

2. Urbach R, Technau GM: Molecular markers for identified neuroblasts in the developing brain of Drosophila. Development 2003, I 30:362I-3637.

3. Bossing T, Udolph G, Doe CQ, Technau GM: The embryonic central nervous system lineages of Drosophila melanogaster. I. Neuroblast lineages derived from the ventral half of the neuroectoderm. Dev Biol 1996, 179:4I-64.

4. Schmidt H, Rickert C, Bossing T, Vef O, Urban J, Technau GM: The embryonic central nervous system lineages of Drosophila melanogaster. II. Neuroblast lineages derived from the dorsal part of the neuroectoderm. Dev Biol 1997, I 89: I86-204.

5. Schmid A, Chiba A, Doe CQ: Clonal analysis of Drosophila embryonic neuroblasts: neural cell types, axon projections and muscle targets. Development 1999, I 26:4653-4689.

6. Bhat KM: Segment polarity genes in neuroblast formation and identity specification during Drosophila neurogenesis. BioEssays 1999, 2 I:472-485.

7. Skeath JB: At the nexus between pattern formation and celltype specification: the generation of individual neuroblast fates in the Drosophila embryonic central nervous system. BioEssays 1999, 21 1:922-931.

8. Technau GM, Berger C, Urbach R: Generation of cell diversity and segmental pattern in the embryonic central nervous system of Drosophila. Dev Dyn 2006, 235:86I-869.

9. Berger C, Urban J, Technau GM: Stage-specific inductive signals in the Drosophila neuroectoderm control the temporal sequence of neuroblast specification. Development 2001, | 28:3243-325I.

10. Prokop A, Technau GM: Early tagma-specific commitment of Drosophila CNS progenitor NBI-I. Development 1994, I 20:2567-2578.

II. Udolph G, Lüer K, Bossing T, Technau GM: Commitment of CNS progenitors along the dorsoventral axis of the Drosophila neuroectoderm. Science 1995, 269:1278-128I.

12. Siegrist SE, Doe CQ: Extrinsic cues orient the cell division axis in Drosophila embryonic neuroblasts. Development 2006, 133:529-536.

13. Nambu JR, Lewis JO, Crews ST: The development and function of the Drosophila CNS midline cells. Comp Biochem Physiol A Comp Physiol 1993, 104:399-409.

14. Jacobs JR: The midline glia of Drosophila: a molecular genetic model for the developmental functions of glia. Prog Neurobiol 2000, 62:475-508.

15. Wheeler SR, Stagg SB, Crews ST: Multiple Notch signaling events control Drosophila CNS midline neurogenesis, gliogenesis and neuronal identity. Development 2008, 135:3071-3079.

16. Golembo M, Raz E, Shilo BZ: The Drosophila embryonic midline is the site of Spitz processing, and induces activation of the EGF receptor in the ventral ectoderm. Development 1996, I 22:3363-3370.

17. Menne T, Lüer K, Technau GM, Klämbt C: CNS midline cells in Drosophila induce the differentiation of lateral neural cells. Development 1997, 1 24:4949-4958.

18. Skeath JB: The Drosophila EGF receptor controls the formation and specification of neuroblasts along the dorsal-ventral axis of the Drosophila embryo. Development 1998, 125:330I-3312.

19. Udolph G, Urban J, Rüsing G, Lüer K, Technau GM: Differential effects of EGF receptor signalling on neuroblast lineages along the dorsoventral axis of the Drosophila CNS. Development 1998, I 25:3292-3299.

20. Yagi Y, Suzuki T, Hayashi S: nteraction between Drosophila IEGF receptor and vnd determines three dorsoventral domains of the neuroectoderm. Development 1998, I 25:3625-3633.

21. Araujo SJ, Tear G: Axon guidance mechanisms and molecules: lessons from invertebrates. Nat Rev Neurosci 2003, 4:910-922.
22. Bossing T, Technau GM: The fate of the CNS midline progenitors in Drosophila as revealed by a new method for single cell labelling. Development 1994, I 20: 1895-1906.

23. Bossing $\mathrm{T}$, Brand $\mathrm{AH}$ : Determination of cell fate along the anteroposterior axis of the Drosophila ventral midline. Development 2006, I33:1001-I0I2.

24. Kearney JB, Wheeler SR, Estes P, Parente B, Crews ST: Gene expression profiling of the developing Drosophila CNS midline cells. Dev Biol 2004, 275:473-492.

25. Wheeler SR, Kearney JB, Guardiola AR, Crews ST: Single-cell mapping of neural and glial gene expression in the developing Drosophila CNS midline cells. Dev Biol 2006, 294:509-524.

26. Giesen K, Hummel T, Stollewerk A, Harrison S, Travers A, Klämbt C: Glial development in the Drosophila CNS requires concomitant activation of glial and repression of neuronal differentiation genes. Development 1997, 124:2307-2316.

27. Hummel T, Schimmelpfeng K, Klämbt C: Commissure formation in the embryonic CNS of Drosophila. I. Identification of the required gene functions. Dev Biol 1999, 209:38I-398.

28. Bergmann A, Tugentman M, Shilo BZ, Steller H: Regulation of cell number by MAPK-dependent control of apoptosis: a mechanism for trophic survival signaling. Dev Cell 2002, 2: I59-I70.

29. Dong R, Jacobs JR: Origin and differentiation of supernumerary midline glia in Drosophila embryos deficient for apoptosis. Dev Biol 1997, I90:165-177.

30. White K, Grether ME, Abrams JM, Young L, Farrell K, Steller H: Genetic control of programmed cell death in Drosophila. Science 1994, 264:677-683.

31. Lüer K, Technau GM: Primary culture of single ectodermal precursors of Drosophila reveals a dorsoventral prepattern of intrinsic neurogenic and epidermogenic capabilities at the early gastrula stage. Development 1992, I I 6:377-385.

32. Halter D, Urban J, Rickert C, Ner S, Ito K, Travers A, Technau GM: The homeobox gene repo is required for the differentiation and maintenance of glia function in the embryonic nervous system of Drosophila melanogaster. Development 1995, | 2 1:317-332.

33. Beckervordersandforth RM, Rickert C, Altenhein B, Technau GM: Subtypes of glial cells in the Drosophila embryonic ventral nerve cord as related to lineage and gene expression. Mech Dev 2008, I 25:542-557.

34. Dittrich R, Bossing T, Gould AP, Technau GM, Urban J: The differentiation of the serotonin neurons in the Drosophila ventral nerve cord depends on the combined function of the zink finger proteins Eagle and Huckebein. Development 1997, I 24:2515-2525

35. Rogulja-Ortmann A, Lüer K, Seibert J, Rickert C, Technau GM: Programmed cell death in the embryonic central nervous system of Drosophila melanogaster. Development 2007, 134:105-116.

36. Udolph G, Prokop A, Bossing T, Technau GM: A common precursor for glia and neurons in the embryonic CNS of Drosophila gives rise to segment-specific lineage variants. Development 1993, I | 8:765-775.

37. Broadus J, Skeath JB, Spana EP, Bossing T, Technau G, Doe CQ: New neuroblast markers and the origin of the aCC/pCC neurons in the Drosophila central nervous system. Mech Dev 1995, 53:393-402.

38. Patel NH, Schafer B, Goodman CS, Holmgren R: The role of segment polarity genes during Drosophila neurogenesis. Genes Dev 1989, 3:890-904.

39. Baines RA, Robinson SG, Fujioka M, Jaynes JB, Bate M: Postsynaptic expression of tetanus toxin light chain blocks synaptogenesis in Drosophila. Curr Biol 1999, 9:1267-1270.

40. Landgraf M, Sánchez-Soriano N, Technau GM, Urban J, Prokop A: Charting the Drosophila neuropile: a strategy for the standardised characterisation of genetically amenable neurites. Dev Biol 2003, 260:207-225.

4I. Lee T, Luo L: Mosaic analysis with a repressible neurotechnique cell marker for studies of gene function in neuronal morphogenesis. Neuron 1999, 22:45I-46I.

42. Klämbt C, Goodman CS: The diversity and pattern of glia during axon pathway formation in the Drosophila embryo. Glia 1991, 14:205-213. 
43. Broadus J, Doe CQ: Extrinsic cues, intrinsic cues and microfilaments regulate asymmetric protein localization in Drosophila neuroblasts. Curr Biol 1997, 7:827-835.

44. Brody T, Odenwald WF: Programmed transformations in neuroblast gene expression during Drosophila CNS lineage development. Dev Biol 2000, 226:34-44.

45. Cross DP, Sang JH: Cell culture of individual Drosophila embryos. I. Development of wild-type cultures. J Embryol Exp Morphol 1978, 45:16I-172.

46. Furst A, Mahowald AP: Differentiation of primary embryonic neuroblasts and purified neural cell cultures from Drosophila. Dev Biol 1985, 109:184-192.

47. Fredieu JR, Mahowald AP: Glial interactions with neurons during Drosophila embryogenesis. Development 1989, 106:739-748.

48. Gerson I, Seecof RL, Teplitz RL: Ultrastructural differentiation during embryonic Drosophila myogenesis in vitro. In Vitro 1976, I 2:615-622.

49. Kim YT, Wu CF: Reversible blockage of neurite development and growth cone formation in neuronal cultures of a temperature-sensitive mutant of Drosophila. J Neurosci 1987, 7:3245-3255.

50. Küppers B, Sanchez-Soriano N, Letzkus J, Technau GM, Prokop A: In developing Drosophila neurones the production of gammaamino butyric acid is tightly regulated downstream of glutamate decarboxylase translation and can be influenced by calcium. J Neurochem 2003, 84:939-95I.

5I. Küppers-Munther B, Letzkus J, Luer K, Technau G, Schmidt H, Prokop A: A new culturing strategy optimises Drosophila primary cell cultures for structural and functional analyses. Dev Biol 2004, 269:459-478.

52. O'Dowd DK: Voltage-gated currents and firing properties of embryonic Drosophila neurons grown in a chemically defined medium. J Neurobiol 1995, 27:113-126.

53. Sakai K, Okamoto H, Hotta Y: Pharmacological characterization of sodium channels in the primary culture of individual Drosophila embryos: neurons of a mutant deficient in a putative sodium channel gene. Cell 1989, 26:107-II8.

54. Schmidt H, Luer K, Hevers W, Technau GM: Ionic currents of Drosophila embryonic neurons derived from selectively cultured CNS midline precursors. J Neurobiol 2000, 44:392-4I3.

55. Seecof RL, Teplitz RL, Gerson I, Ikeda K, Donady JJ: Differentiation of neuromuscular junctions in cultures of embryonic Drosophila cells. Proc Natl Acad Sci USA 1972, 69:566-570.

56. Seecof RL, Donady JJ, Teplitz RL: Differentiation of Drosophila neuroblasts to form ganglion-type clusters of neurons in vitro. Cell Diff 1973, 2:143-149.

57. Sepp KJ, Hong P, Lizarraga SB, Liu JS, Mejia LA, Walsh CA, Perrimon $\mathrm{N}$ : Identification of neural outgrowth genes using genomewide RNAi. PLoS Gen 2008, 4:e I000III.

58. Technau GM: A single cell approach to problems of cell lineage and commitment during embryogenesis of Drosophila melanogaster. Development 1987, 100:1-12.

59. Nambu JR, Lewis JO, Wharton KA, Crews ST: The Drosophila single-minded gene encodes a helix-loop-helix protein that acts as a master regulator of CNS midline development. Cell I99I, 67:1157-1167.

60. Prokop A, Bray S, Harrison E, Technau GM: Homeotic regulation of segment-specific differences in neuroblast numbers and proliferation in the Drosophila central nervous system. Mech Dev 1998, 74:99-II0.

61. Sepp KJ, Schulte J, Auld VJ: Peripheral glia direct axon guidance across the CNS/PNS transition zone. Dev Biol 200I, 238:47-63.

62. Ito K, Urban J, Technau GM: Distribution, classification and development of Drosophila glial cells in the late embryonic and early larval ventral nerve cord. Roux's Arch Dev Biol 1995, 204:284-307.

63. Brand $\mathrm{AH}$, Perrimon $\mathrm{N}$ : Targeted gene expression as a means of altering cell fates and generating dominant phenotypes. Development 1993, I | 8:40|-415.

64. Schneider I: Differentiation of larval Drosophila eye-antennal discs in vitro. J Exp Zool 1964, 1 56:9|-104.

65. Seecof RL, Alleaume N, Teplitz RL, Gerson I: Differentiation of neurons and myocytes in cell cultures made from Drosophila gastrulae. Exp Cell Res 1971, 69:161-173.

66. Shields G, Sang JH: Improved medium for culture of Drosophila embryonic cells. D IS 1977, 52:161.
67. Campos-Ortega JA, Hartenstein V: The Embryonic Development of Drosophila melanogaster Berlin, Heidelberg, New York: Springer; 1997.

68. Dübendorfer A, Eichenberger-Glinz S: Development and metamorphosis of larval and adult tissues of Drosophila in vitro. In Invertebrate Systems In Vitro Edited by: Kurstak E, Maramorosch K, Dübendorfer A. Amsterdam: Elsevier North Holland; 1980:169-I85.

69. Hartenstein V, Rudloff $E$, Campos-Ortega JA: The pattern of proliferation of the neuroblasts in the wild-type embryo of Drosophila melanogaster. Roux's Arch Dev Biol 1987, 196:473-485.
Publish with Bio Med Central and every scientist can read your work free of charge

"BioMed Central will be the most significant development for disseminating the results of biomedical research in our lifetime. "

Sir Paul Nurse, Cancer Research UK

Your research papers will be:

- available free of charge to the entire biomedical community

- peer reviewed and published immediately upon acceptance

- cited in PubMed and archived on PubMed Central

- yours - you keep the copyright

Submit your manuscript here:

http://www.biomedcentral.com/info/publishing_adv.asp
BiolMedcentral 